\title{
Fundamentos Econômicos e Quantitativos no Planejamento Turístico
}

\author{
Wilson Abrahão Rabahy*
}

\begin{abstract}
RESUMO: A teoria que fundomenta o planejamento do turismo destaca a importancia de três conjuntos de fatores que interferem no desenvolvónento do setor: os representativos da demanda, os da oferta-incluindo o próprio atrativo turlstico - e os de ligaçäo, caracterizados pela distância $e$ acessibilidade entre os centros receptivos e emissores. A medida da influência de alguns desses fatores e a construçâo de modelos de previsäo do turismo sāo efetivados como apoio da Teorometria - técnica de aplicação dos métodos econométricos à investigaçâo do fenômeno turístico.

A elaboração de un modelo teorométrico de previsōes do setor baseia-se em conhecimentos cientificos do turismo e da Economia, além de apoiar-se em fundamentos da Matemática e da Estatística, requeridos pela Econometria. A partir da construçâo desses modelos, pode-se realizar experimentos que, testados e comprovados, fornecem novas bases de conhecimento cientffico do turisno, além de permitir antlises e previsōes mais realistas do fenômeno em estudo.

Alguns desses experimentos teorométricos, bem como sua aplicaçäo num particular caso do turismo brasileiro, säo aqui desenvolvidos, e seus resultados confirmam a validade deste trabalho científico, reduzindo a margem de erro das previsōes e fundamentando melhor as decisōes de política econômica.
\end{abstract}

UNITERMOS: Turismo: estatistica, planejamento, efeitos e fatores sócio-econômicos, modelos de previsão; teorometria.

ABSTRACT: The theory in which tourism planning is based emphasizes the importance of three factors in the development of the sector: social and economic, psycho-sociological and technical. The measurement of the effects of some of these factors and the construction of models for tourism forecasts are object of the econometric treatment. The paricular use of econometric investigation methods of the tourism phenomenon is named theorometrics. The elaboration of a theorometric model for forecasts in the sector is based on scientific

by theoretical statements of Mathematics and Statistics required by Econometrics.

Experiments can be done after the construction of these models, and once tested and conformed, they provide new basisfor the tourism scientific

(*) Professor Associado (Livre-Docente) do Curso de Turismo da ECAJUSP. ECAVUSP - Cidade Universitária "Arnando de Salles Oliveira" - Av. Prof. Lúcio Martins Rodrigues, 443 - 05508 - São Paulo - SP - Brasil 
KEY WORDS: Tourism: statistics, plavoing, social-economic factors and effects, prevision models; theorometrics.

\section{INTRODUÇĀO}

A avaliação dos efeitos do turismo constitui uma tarefa complexa, pelas dificuldades na obtenção de estatísticas necessárias e padronizadas para diversos países envolvidos e pelo estágio metodológico atual dos estudos e análise do setor Serviços, onde se inclui o turismo. No entanto, dado o seu caráter multidisciplinar, também se classifica como setor industrial, com implicações no setor primário. Essa condição requer que se promova um tratamento integrado na sua avaliação, o que, por si sర, se constitui num desafio metodológico.

O impacto do turismo nas condiçōes econômicas e sociais dos países se manifesta de forma diferenciada, segundo as características e tipicidades de cada localidade. Nos países mais desenvolvidos os impactos da atividade turística tendem a ser mais significativos do que nos países em desenvolvimento, embora em termos relativos revele-se mais importante para a economia dos países menos desenvolvidos. Essas considerações recomendam que se proceda à avaliaçāo dos efeitos do turismo por grupos homogêneas de países, a exemplo da classificação proposta pela ( )MT

O turismo, a par dos benefícios que oropicia, é modernamente reconhecido como uma importante atividade econômica, que, além de seus efeitos inerentes, também acarreta umpactos nas áreas sociais, culturais e políticas.

No campo económico, já se tem salientado os seus efeitos na geração de divisas, de renda e de emprego, assim como são destacados os seus impactos na distribuição regional, nas finanças públicas e nos níveis gerais de preços.

Esses efeitos, chamados económicos, também poderiam estar classificados como de natureza sócio-cultural, dadas as suas interaçōes. Como impactos mais característicos desse campo sరccio-cultural, pode-se, entre outros, destacar. o impacto no meio ambiente: no parnimónio histórico-cultural: no desenvolvimento dos recursos humanos, e nas mudanças sócio-culturais da população, inclusive de hábito de consumo.

36
Para uma adequada avaliação dos efeitos sócio-económicos do turismo é necessário, ainda, que se analise e se quantifique a importância dos principais fatores intervenientes. Esses fatores que, num prisma económico, representam as forças de mercado - a demanda, a oferta e a acessibilidade -, podem ser agregados em três grandes grupos: fatores sócio-económicos; fatores naturais culturais e psico-sociológicos; e fatores técnicos.

Entre os fatores sócio-econômicos, os mais evidentes são: o tamanho e a composição etária da população dos centros emissores; nível e a distribuição de renda, tanto do receptivo quanto, e especialmente, do emissivo; os níveis de preço e câmbio relativos entre o receptivo, o emissivo e as destinaçōes alternativas; o grau de urbanização, de industrialização e o ciclo dos negócios dos emissivos; e o tempo livre para o lazer desses centros.2.3.4

Quanto aos fatores naturais, culturais e psico-sociológicos, dois aspectos merecem ser ressaltados. Primeiro, é que o atrativo turístico, em geral o natural, é a essência dessa atividade, além de sua localização geográfica; e, segundo, é que os fatores econômicos nāo atuam isoladamente sobre as decisōes dos consumidores. Estas sáo formadas em um contexto mais amplo, onde interferem também os condicionantes culturais e psico-sociais. ${ }^{5}$

O grupo formado pelos fatores técnicos pode ser apresentado em quatro subconjuntos de fatores: os mecanismos institucionais de intervenção; a evolução do sistema de transportes, inclusive de seu custo e tempo; a infra-estrutura urbana e turística disponível; e os operadores turísticos.

Analisados esses fatores intervenientes, permanecem as questōes de sua quantificaçāo e a de seus efeitos. As técnicas de quantificação no pianejamento turístico são formas que modernamente vêm sendo desenvolvidas e se constituem no otjeto desse trabalho.

\section{MÉTODOS QUANTITATIVOS NO PLANEJAMENTO TURISTICO ${ }^{6}$}

\subsection{Conceitos Básicos - A Teorometria}

Såo múltiplos os procedimentos tradicionalmente utilizados na obtenção de previsōes do comportamento turístico, mas a utilizaçăo específica de modelos econométricos vem demonstrando que esta uma das técnicas mais adequadas para o estabelecimento de relaçōes futuras entre os componentes determinados das estruturas turísticas sobretudo em uma dimensão de médio prazo. 
A Econometria se distingue da Matemática Econômica e da E6tatística Econônica, embora seja bastante relacionada a ambas e utilize resultados propiciados por esses métodos científicos. O método da investigação econométrica pretende, essencialmente, unir a teoria oconômica às mediçōes reais, e, para isso, a técnica estatística é empregada como ponte. ${ }^{(9,10)}$

A Econometria apóia-se na Teoria Económica para definir as teorias, leis ou hipóteses que se deseja investigar, e utiliza, como instrumentos auxiliares, a Matemática e a Estatística para a sua especificação, estimação e verificação. Uma vez definidas as expressões quantitativas dos elementos teóricos, fornecidos pelos modelos adotados, recorre novamente à Teoria Económica, para interpretar e avaliar os resultados observados, que poderão fundamentar a definição dos instrumentos mais adequados à consecução dos objetivos da política econômica estabelecida. ${ }^{111,12}$

$\mathrm{Na}$ forma desta colocação, pode-se, entāo, definir Econometria como sendo o ramo das ciências económicas encarregado de verificar as hipóteses e teorias formuladas pela Ciência Econômica, utilizando-se dos instrumentais dados pela Matemática e pela Estatística. ${ }^{14}$ A base dessas verificações são modelos econométricos, que consistem em representação e quantificação abstratas e simplificadas da realidade dos fatos, atendo-se aos fatores mais fundamentais para verificar o sentido de direção do fenômeno em estudo.

A particular aplicação dos métodos econométricos na investigação do fenômeno turístico tem sido designada pelo termo Teorometria, e considerada como uma modalidade da Econometria. $\mathrm{Na}$ verdade, duas expressões surgiram para conceituar essa nova atividade científica, que procura construir e quantificar modelos para o setor turístico: Turistometria, proposta por Defert, e Teorometria, termo consagrado, sugerido por Alcaide, apoiado por outros estudiosos e considerado mais apropriado pelo Professor Fernandez Galiano, catedrático da Língua Grega, da Universidade de Madrid. ${ }^{15}$

O tratamento dado às análises quantitativas do turismo, em geral, tem-se limitado à aplicação de simples técnicas estatísticas, sem buscar estabelecer as relações existentes entre os fatores envolvidos, e com poucas perspectivas de integrá-los num contexto mais amplo de investigação, construído pelo conhecimento teórico, que o caracterizaria como científico.

A análise econométrica se inicia no momento em que se relacionam, ou se encadeiam entre si, os distintos aspectos ou fatores determinantes do setor turístico. Com a seleção de variáveis, que possam bem representar a realidade, e de sua inter-relação, indicam-se os modelos econométricos pela teoria ou por experimentos compro38 vados. Estes são elaborados, buscando explicar o comportamento e a magnitude do setor turístico, nos aspectos que se pretende analisar, os quais são representados simplificadamente.

O impacto do turismo nos vários campos de atividade de uma sociedade já foi objeto de referência. Alguns desses efeitos e suas inter-relações com outros elementos da realidade sāo objetos de medidas e indicações de tendências com a aplicação de modelos econométricos.

\subsection{Proposta de um Modelo Experimental}

As questōes centrais na formulação de um modelo consistem na definição dos objetos do estudo e na disponibilidade e qualidade dos dados necessários. 16

Basicamente as informações são obtidas por pesquisas diretas ou fontes de dados secundários. A primeira alternativa apresenta muitas vantagens em relação aos dados existentes, principalmente porque permite dirigir o levantamento às questões específicas, requeridas pelos modelos. De outro lado, apresenta uma série de restriçōes, destacando-se o problema dos custos de uma pesquisa dessa natureza e os problemas da qualidade das informações. Não sendo um levantamento censitário, e não dispondo dos mecanismos institucionais de controle, a amostra pesquisada pode não representar adequadamente o verdadeiro fluxo turístico, contendo visões de estatísticas de fronteiras, dupla contagem etc. É também sensível a época de sua realização, em função de sazonalidade da atividade turística, de medidas de política económica adotadas pelos países emissores/receptores ou, ainda, do ciclo económico vivido por esses países.

A alternativa mais viável acaba sendo a utilização de fontes de dados secundários, destacando-se no turismo a OMT - Organização Mundial do Turismo para estatísticas internacionais, e a Embratur Empresa Brasileira de Turismo, para dados nacionais. ${ }^{17}$

Dado que os modelos de previsăo turfstica pressupōem inter-relação com outros setores, destacando-se o econômico por sua importância e possibilidade de quantificação, alguns dos principais dados representativos desse setor também devem ser levantados, ao lado das informações turísticas. As fontes de dados das variáveis econômicas são mais amplas, e são referidas quando utilizadas.

\subsubsection{Objeto do Modelo}

O campo de abrangência desse experimento se restringe à avaljøçăo da demanda do turismo internacional no Brasil, segundo os 
principais países emissores. Essa demanda é bastante concentrada, de modo que apenas quatro países são responsáveis por cerca de $50 \%$ do respectivo total brasileiro: Argentina (30,0\%, em média nos últimos três anos), Estados Unidos (12,0\%), Uruguai $(10,5 \%)$ e Paraguai $(7,0 \%)$. De uma forma geral, quatro países da América do Sul (Argentina, Paraguai, Uruguai, Chile) respondem, em média, por $50 \%$, enquanto que os Estados Unidos $(12,0 \%)$ mais cinco parses da Europa $(14,0 \%)$ - Itália, Alemanha, Espanha e Inglaterra - explicam outros $26,0 \%$, perfazendo juntos $76,0 \%$ das entradas de turistas no Brasil.

A partir dessas características, esse experimento concentra-se na elaboração de três modelos básicos:

a) modelo estimativo da demanda dos países da América do Sul, simplificadamente composto por um de seus mais significativos representantes, a Argentina;

b) modelo especificativo da demanda dos Estados Unidos mais parses da Europa, podendo-se trabalhar com sub-modelos, em função de seus resultados, em resposta às variáveis selecionadas;

c) modelo de previsão da demånda global.

\subsubsection{Escolha das Varióveis do Modelo}

Os fluxos internacionais de turistas ao Brasil, assim como às ouras regiōes do mundo, são determinados por fatores de oferta, de demanda e da interação entre os mesmos. Em termos genéricos, pode-se classificar os fatores da oferta em três grupos:

a) atrativos turísticos disponíveis;

b) infra-estrutura urbana mais equipamentos turísticos disponíveis; e

c) condicionantes sócio-económicos, preços, câmbio, renda - de al-

ta relevância - e questōes políticas, culturais, sociais e mesmo de segurança.

A dificuldade de se dispor de estatísticas representativas dos fatores físicos e dos sociais, políticos e culturais faz com que a maio ria dos experimentos selecione, basicamente, as variáveis econômicas, para compor a força da oferta no modelo.

Além das dificuldades estatísticas, essas variáveis são de natureza basicamente estrutural, năo se modifícando em curto prazo, e em geral, representadas pelo fluxo em tempo anterior. Na verdade, esse fluxo anterior representa um conjunto mais amplo de fatores, como as facilidades e custos de acesso; as identidades de costumes e tradiçōes; os hábitos; as facilidades de comunicaçōes; a publicidade direta dos visitantes; enfim, substitui uma série de variáveis, dimi- nuindo a importância da explicação da componente aleatória residual.

Ao lado dessa variável, são ainda selecionados como fatores determinantes da oferta o preço, o câmbio e a renda, sendo esse último adotado como indicador síntese das condiçōes económicas do país receptor, no caso o Brasil. Convém ressaltar que, tal qual outro bem de consumo, o turismo brasileiro tem "substitutos", razão por que o preço e o câmbio serão traduzidos em termos relativos aos de seus concorrentes, além de sê-lo também com relação ao país emissor.

As características de rigidez de boa parte dos fatores de oferta, basicamente os atrativos turísticos e os equipamentos disponiveis, considerados fixos no curto prazo, têm ressaltado a importância dos fatores da demanda na determinação dos fluxos turísticos. Acrescese a isso o fato de que algumas das variáveis da oferta, como o preço e o câmbio, são relevantes quando relativizados aos dos paŕses emissores e dos países substitutos.

A relação de variáveis que representam o lado da demanda é ampla e envolve também os aspectos econômicos, sociais, culturais e políticos. A correlação entre esses fatores é muito alta, e já foi objeto de consideraçōes teóricas anteriores. Dada a estreita associação entre nível de renda, nível cultural e grau de escolaridade, por exemplo, a utilização de uma das variáveis, no caso a renda, tem sido adotada como resultado síntese dos impactos desses fatores.

Outros fatores de demanda menos diretamente associados à renda são o preço, o câmbio (já referidos) e o tamanho do mercado consumidor, representados, em geral, pela população ou pelo número de inđivíduos com renda superior a, por exemplo, 5.000 dólares anuais. Na verdace, essa última variável tambên pode ser vista como um fator fixo, no curto prazo, devidamente incorporado nos resultados dos fluxos anteriores.

As variáveis preço e câmbio merecem algumas ressalvas. Os problemas principais relativos ao câmbio referem-se ao momento da medida, face ao de sua variação, e ao tipo de câmbio possível de utilização, quase sempre o câmbio oficial, para o qual se dispōe de informações, e cujos resultados contabilizados não representam adequadamente a realidade. Quanto à questão do momento da medida, recomenda-se que se trabalhe com dados mensais, se possivel trimestrais, pois os valores médios anuais podem neutralizar e não refletir os reais efeitos do câmbio nos fluxos turísticos. Os problemas relativos aos preços referem-se à ausência de um indicador especifico do custo do turismo, em geral substituído por índices de preços ao consumidor

Nos modelos econométricos da previsāo turística são ainda des- 
tacados os fatores de interaçåo entre as variáveis de oferta e de demanda, representados, principalmente, pelos componentes: distância, em termos geográficos, de tempo de viagem ou de custo, entre o emissor e o receptor; e grau de relação político, cultural e econômico existeate entre os países, medido pelo fluxo exportação/importaça, fluxo turístico anterior, fluxos diversos (número de chamadas telefónicas, número e freqǚ̂ncia de vóos etc.) e por informaçōes quaditative, dadas, por exemplo, peło processo de formação histórica dos países.

\subsubsection{Formulaşáo de Hipóteses}

Definidas as variáreis explicativas, a questāo da especificação fica dependente da form da função, delineada pelo tipo de tendência dessas varitureis e das hipóteses a serem propostas na construção dos modelos. Com base no diagnóstico realizado e em resultados de outros experimentos, wâo formuladas as seguintes hipóteses:

a) os fluxos intra-regionais apresentam maiores nfveis de sensibilidade às flutuaçōes conjunturais de alguns fatores determinantes do centro receptivo;

b) os fluxos inter-regionais são menos sensíveis às variaçōes de curto prazo desses mesmos fatores, devendo, de outro lado, revelar resultados mais significativos nos ajustamentos da tendência secular e baseados, especialmente, nos resultados de seus próprios fatores determinantes nos fatores da demanda;

c) os fluxos inter-regionais, associados à demanda dos principais paises emissores mundiais (para os quais o Brasil é apenas um destino marginal), tendem a apresentar maior sensibilidade, na forma da tendência, em resposta a campanhas promocionais, acontecimentos especiais e outros eventos dessa natureza.

Consideram-se integrantes do grupo intra-regional os paises da América do Sul, especialmente os localizados na região Centro-Sul, para os quais os custos de transportes não são os mais relevantes, e as questōes de câmbio e preço são mais valorizadas. Para três dos parses desse grupo - Argentina, Uruguai, Paraguai - importantes emissores de turistas ao Brasil, respectivamente $33,2,12,1$ e $5,9 \%$, com o destino brasileiro em suas emissōes totais é significativo e superior a $20 \%$.

Os fluxos inter-regionais são caracterizados por centros emissores da Europa e pelos Estados Unidos, os quais não dispōem do mesmo grau das variaçóes conjunturais dos fatores da oferta, e que, ałém disso, sāo menos valorizados por esses países, face ao seu ní- vel de renda e à importância do custo de transporte no custo total da viagem. A participação relativa da destinação Brasil situa-se próxima dos $0,1 \%$ para a Alemanha e França, e de $0,5 \%$ para a Itália e os Estados Unidos

\subsubsection{Especifícação do Modelo}

Dadas as restriçōes estatísticas salientadas e com vistas a facilitar a agregação dos dados, baseados em funçōes com diferentes tendências evolutivas, o experimento utiliza modelos uniequacionais, constituídos de funçōes lineares ou linearizáveis.

\section{RESULTADOS DO MODELO EXPERIMENTAL}

A formulação dos modelos de avaliação da demanda internacional de turismo no Brasil baseia-se nos fundamentos teóricos e econométricos referidos nos itens 1 e 2 , envolvendo as questões da escolha das variáveis e a forma das funções especificativas. As suas estimativas podem ser procedidas com base nos valores do receptivo total ou constitufdas pela agregação dos resultados parciais dos principais centros emissores.

Dada a finalidade de desenvolver um método quantitativo e objetivo de apoio ao planejamento turístico brasileiro, realizaram-se as duas formas alternativas e interativas de previsão e análise, procedidas com algumas simplificaçōes. Para compor o modelo agregativo, foram selecionados três palses: a Argentina, representando os parses da América do Sul (60\%), os Estados Unidos, representando a América do Norte (17\%), e a Alemanha, representando a Europa (20\%). Os resultados de cada um desses modelos são utilizados nos testes de comprovação das hipóteses formuladas, sendo a Argentina representante dos Centros emissores intra-regionais, e os Estados Unidos e a Alemanha, representantes dos inter-regionais.

\subsection{Modelo de Previsão do Fluxo América do Sul: Argentina}

Para a construção do modelo explicativo do número de turistas da Argentina foram, inicialmente, selecionadas 14 variáveis, salientando-se os fatores de oferta e suas relaçóes com os correspondentes fatores de demanda ou dos "bens substitutos" (destinos alternati- 
vos). Naturalmente, o fator de demanda renda. representado pelo PIB - Produto Interno Bruto -, também fol objeto de ênfase espe. cial.

A análise da matriz de correlação revela a estreita associaçāo entre vários dos fatores relacionados, sugerindo que a construçāo do modelo se faça na análise de melhoramento, de modo a evitar problemas de multicolinearidade.

Realizadas diversas aproximaçōes, optou-se pelo modelo n\& forma logarimica, que apresentou os melhores resultados, confirmados pelos testes estatísticos - sem necessidade de se adotar variáveis auxiliares "dummies" -, conforme pode-se depreender dos dados descritos a seguir:

Função estimada

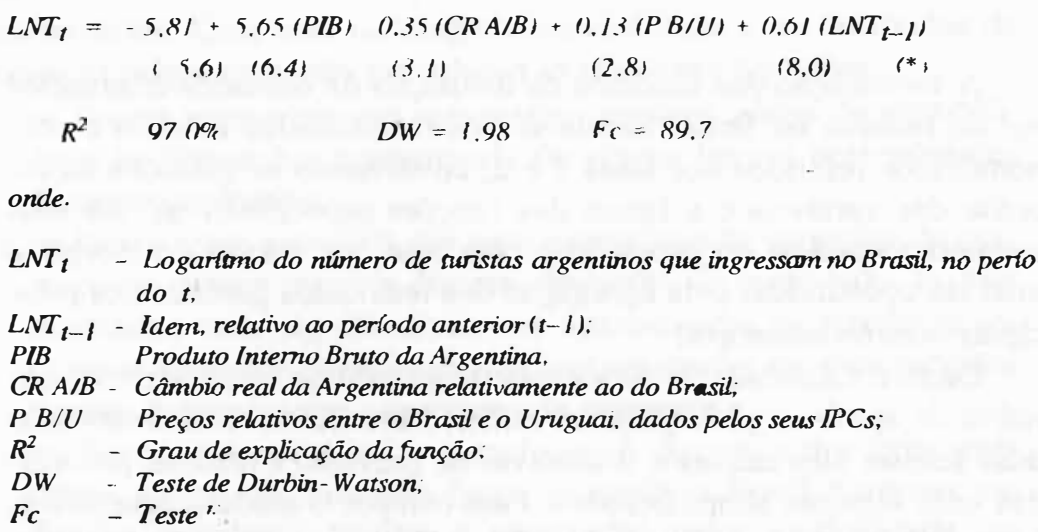

$L N T_{t}$ - Logartamo do número de saristas argentinos que ingressan no Brasil, no perío do $t$,

$L N T_{t-1}$ - Idem, relativo ao perfodo anterior ( $\left.t-1\right)$.

PIB Produto Interno Bruto da Argentina.

$C R A / B$ - Câmbio real da Argentina relativamente ao do Brasil.

$P B / U$ Preços relativos entre o Brasil e o Uruguai. dados pelos seus IPCS,

$R^{2} \quad$ - Grau de explicaçāo da funçäo.

DW Teste de Durbin-Watson

Fc - Teste'.

* Os números entre parênteses referem-se aos valores do Teste t dos coeficientes.

Desta forma, a partir das variáveis exógenas - PIB, CR(A/B), $\mathrm{CR}(\mathrm{B} / \mathrm{U})$ e $\mathrm{T}_{t-1}-$, pode-se inferir os resultados prováveis da entrada de turistas argentinos no Brasil (Figura 1), destacando-se a sua consistência com as fundamentaçōes teóricas discutidas anteriormente.

\subsection{Modelos de Previsão dos Fluxos da América do Norte e Eu- ropa: Estados Unidos e Alemanha}

As hipóteses formuladas para os fluxos turísticos inter-regionais. representados pelos países emissores Alemanha e Estados Unidos, pressupōem uma maior sensibilidade aos fatores explicativos de de-
FIGURA 1 - ARGENTINA - CONFRONTO DA EVOLUÇĀO DOS ÍNDICES DO NÚMERO DE TURISTAS INGRESSOS NO BRASIL COM OS RESULTADOS ESTIMADOS - 1972 a 1986

(Base: $1970=100)$

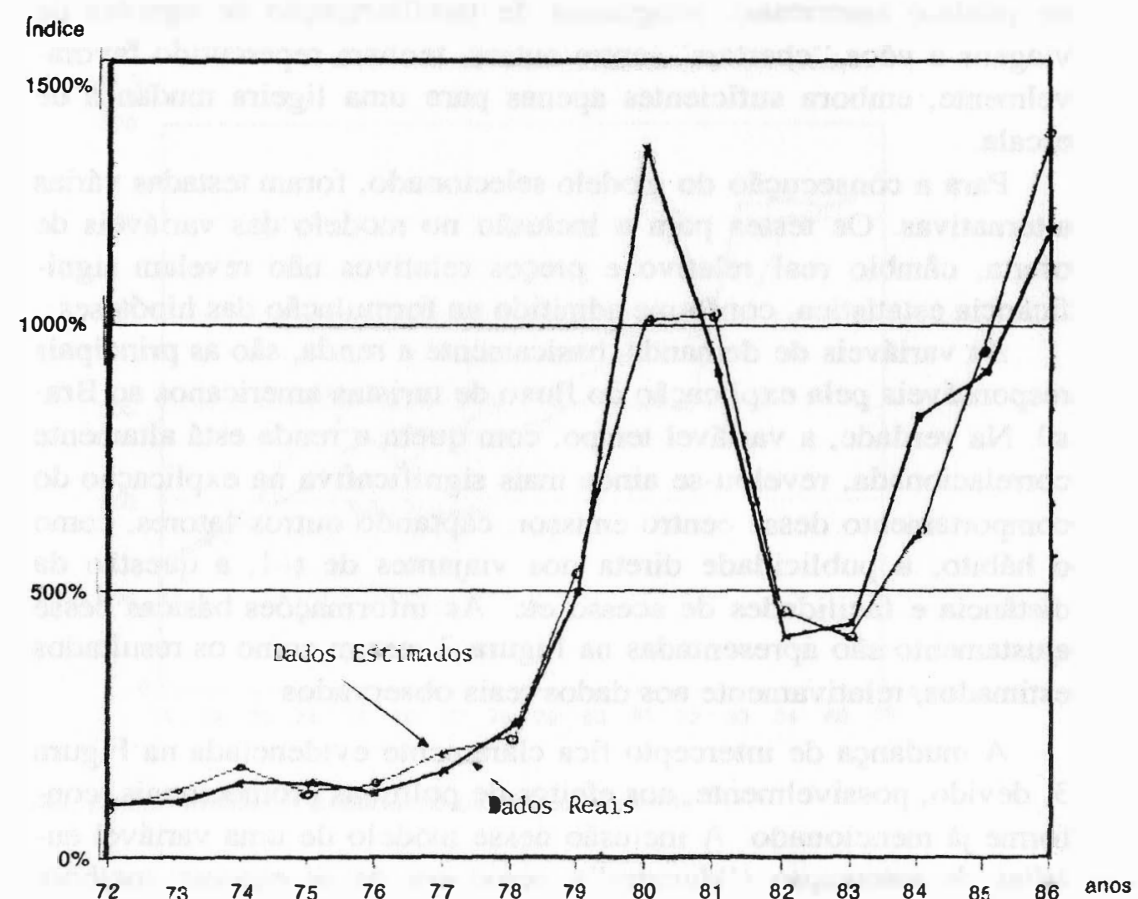

Fonte: Dados extraídos de Anuários Estatsticos da Embratur ${ }^{17}$

manda, colocando num segundo plano as variáveis econômicas do lado da oferta. As justificativas dessa proposição são encontradas na maior participação relativa do custo de transporte, tornando menos relevantes os gastos turísticos locais; na renda real desses centros, relativamente mais altas; e no menor grau de informaçāo sobre as variáveis do local de destino. Além disso, a destinaçāo brasileira, apesar de seu alto potencial turístico, ainda não apresenta relevância para esses países - menos de 0,5\% do total emissivo. Assim sendo, em funçāo de acontecimentos especiais ou de campanhas promocionais, por exemplo, os fluxos tuŕ́sticos podem alterar o patamar de sua tendência, sem, necessaniamente, modificar o seu ritmo de evolução. 
No caso dos Estados linidos essa situação e claramente verifi cada a partir de 1983. sugerindo que decisōes promocionals de anos anteriores, tais como instalação de representação de órgãos do turismo brasileiro em Nova York, campanhas promocionais dirigidas ao público americano, programas de familiarização de agentes de viagens e vóos "charters". entre outros, tenham repercutido favoravelmente, embora suficientes apenas para uma ligeira mudança de escala.

Para a consecuçăo do modelo selecionado, foram testadas várias a)temativas. Os testes para a inclusão no modelo das variáveis de oferta, câmbio real relativo e preços relativos não revelam significância estatística, conforme admitido na formulação das hipóteses.

As variáveis de demanda, basicamente a renda, são as principais responsáveis pela explicação do fluxo de turistas americanos ao Brasil. Na verdade, a variável tempo. com quem a renda está altamente correlacionada, revelou-se ainda mais significativa na explicação do comportamento desse centro emissor. captando outros fatores, como o hábito, a publicidade direta dos viajantes de $1-1$. a questão da distância e facilidades de acesso etc As ınformaçōes básicas desse ajustamento são apresentadas na Figura 2. assım como os resultados estimados, relativamente aos dados reais observados

A mudança de intercepto fica claramente evıdenciada na Figura 3, devido, possivelmente, aos efeitos de políticas promocionais, conforme já mencionado. A inclusão nesse modelo de uma variável auxiliar de intercepto ("dummy"), como era de se esperar, melhora substancialmente o poder explicativo da regressảo e os níveis de significância estatística dos parâmetros ( )s resultados desse novo ajustamento podem ser visualizados na Figura 3

\subsubsection{Alemanha}

Para o caso da Alemanha, a situação não é substancialmente diferente. Os fluxos de turistas alemáes para o Brasil evoluem ao longo do tempo, independentemente das flutuaçōes conjunturais de alguns indicadores económicos do lado da oferta. Porém, revelam-se sensíveis às mudanças de sua própria conjuntura económica e das perspectivas da economia mundial

Convém ressaltar que. assim como para os demais parses da Eu. ropa, para a Alemanha a destinação Brasil não apresenta significado
FIGURA 2 - ESTADOS UNIDOS - CONFRONTO DA EVOLUÇ̃̃O DO ÍNDICE DO NÚMERO DE TURISTAS INGRESSOS NO BRASIL COM OS RESULTADOS ESTIMADOS - 1971 a 1986 (Base: $1970=100$ )

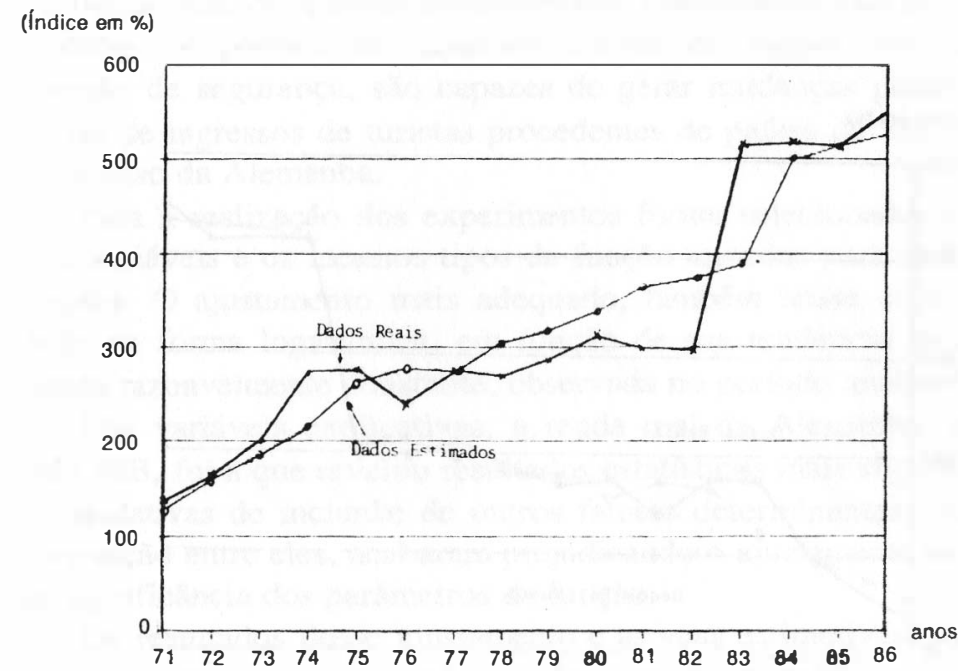

Fonte: Dados extraídos de Anuários Estatísticas da Embratur ${ }^{17}$

Funçäo estimada:

$$
\begin{aligned}
T_{E U}= & 1.046+0,256(t) \\
& (3,05) \quad(5,17)
\end{aligned}
$$$$
\text { onde: }
$$

$T_{E U}-$ Fluxo de turistas americanos,

$t$-Tempo;

* - Os números entre parênteses referem-se aos valores do Teste $t$ dos coeficientes. 
FIGURA 3 - ESTADOS UNIDOS - CONFRONTO DA EVOLUÇĀO DO INDICE DO NUMERO DE TURISTAS INGRESSOS NO BRASIL COM

OS RESULTADOS ESTIMADOS, USANDO VARIÁVEL AUXILIAR 1971 a 1986 (Base: $1970=100)$

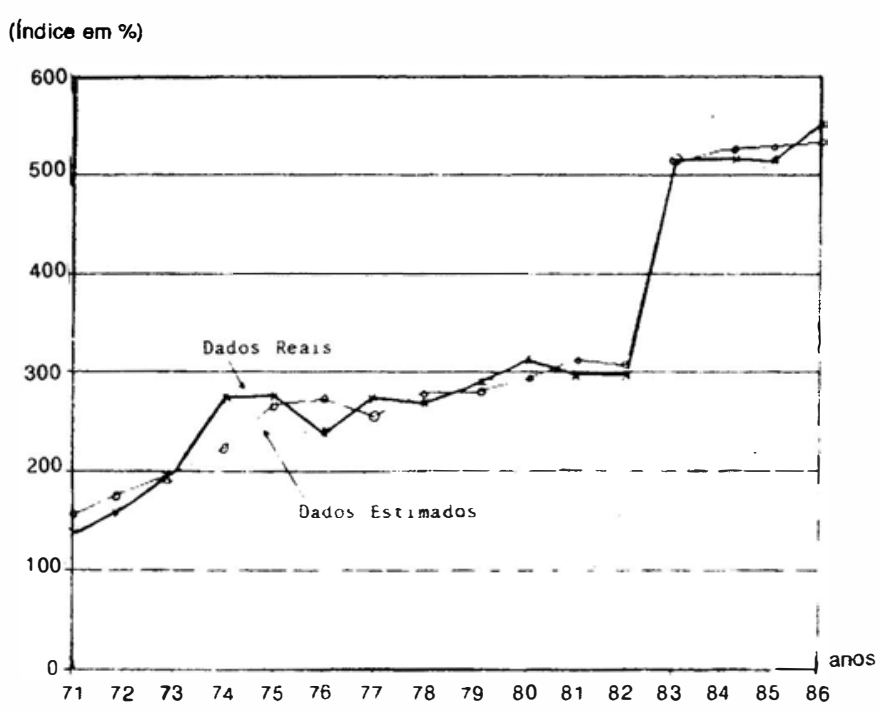

Fonte. Dados extrafdos de Anuáirios Estatísticos da Embratur ${ }^{17}$

\section{Funçāo estionada.}

$$
\begin{aligned}
T_{E U}= & 2.073+0,084(t)+2.012(D) \\
& (11.40) \quad(2,39) \quad(7,81) \quad(*)
\end{aligned}
$$$$
R^{2}=97,5 \quad D W=2,06 \quad F C=253,8
$$

onde:

D - Variável auriliar ("dionony"):

* - Os números entre parênteses referem-se aos valores do Teste t dos coeficientes. especial - apenas $0,1 \%$ de seu mercado emissivo. Essa característica, aliada ao potencial turístico brasileiro, sugere a possibilidade de mudanças substanciais na escala da tendência, sem que isso seja necessariamente explicado pelos fatores econômicos, dada sua condição de mercado marginal. Fatores de segurança, por exemplo, podem ser mais determinantes para a redução do fluxo de turistas do que qualquer tipo de aumento do custo da viagem (câmbio e preços). De outro lado, campanhas promocionais, complementadas por outras medidas de política de desenvolvimento do turista, incluindo a questão de segurança, são capazes de gerar mudanças positivas na escala de ingressos de turistas procedentes de países da Europa, como o caso da Alemanha.

Para a realização dos experimentos foram selecionadas as mesmas variáveis e os mesmos tipos de função testados para os Estados Unidos. $O$ ajustamento mais adequado, também nesse caso, não é dado na forma logarítmica, em função de sua tendência de crescimento razoavelmente constante, observada no período analisado

Das variáveis explicativas, a renda real da Alemanha, medida pelo PIB, foi a que revelou resultados estatísticos mais significantes. As tentativas de inclusăo de outros fatores determinantes, pela alta correlação entre eles, acabaram prejudicando o ajustamento e o nível de significância dos parâmetros da função.

Os resultados desse ajustamento e as suas estimativas, confrontadas com os dados observados, podem ser vistos na Figura 4.

\subsection{Modelos de Previsāo do Receptivo Total}

Para a previsão do número total de turistas ingressos no Brasil foram adotadas duas soluções: a construção de um modelo de ajustamento do receptivo total e a elaboração de um sistema de modelos interativos, cujos resultados globais são dados pela agregação das estimativas parciais.

O primeiro tipo de solução recoloca a questão dos fatores explicativos, com a diferença de que, do lado da demanda, as variáveis são dadas em termos agregados, representando o conjunto dos países emissores. Um critério adequado para assegurar essa representatividade seria dado pela agregação ponderada das variáveis, onde cada pars participaria com pesos distintos, dados pela sua importância relativa média no receptivo brasileiro, nos últimos anos.

Neste experimento adotou-se a renda real mundial média, dada pelo PIB, como uma aproximação dessa medida desejável Para veri ficar-se a destacada importância da Argentina no receptivo total - a 
FIGURA 4 - ALEMANHA - CONFRONTO DA EVOLUÇÃO DO

ÍNDICE DO NÚMERO DE TURISTAS INGRESSOS NO BRASIL COM OS RESULTADOS ESTIMADOS - 1970 a $1986($ Base: $1970=100)$

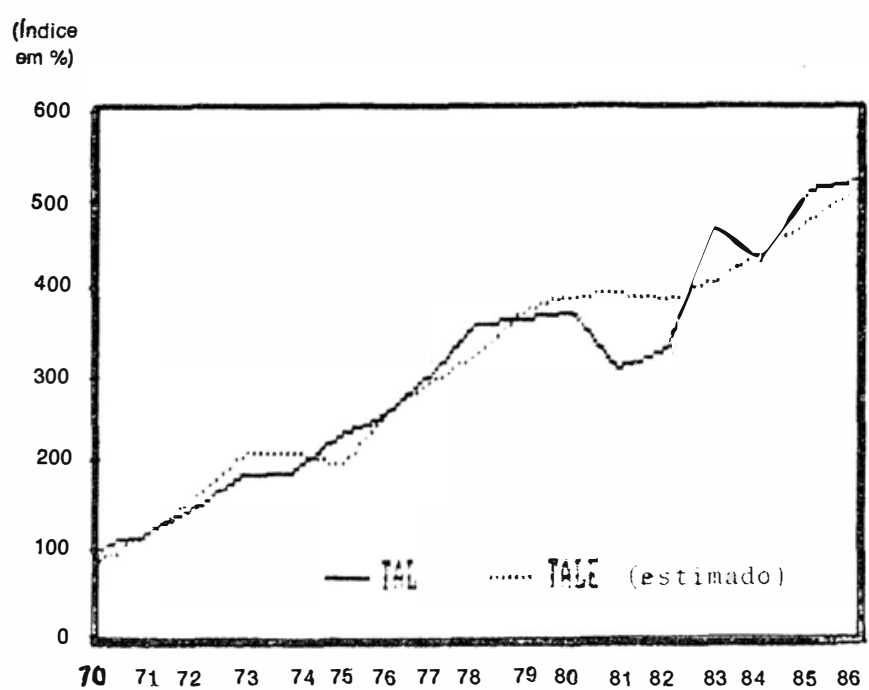

Fonte: Dados extraidos de Anuários Estatssticos da Embratur ${ }^{17}$

Funçāo estionada:

$T_{A L}=-8,994+9,854\left(P I B_{A L}\right)$

$(-10,61)(14,27) \quad(*)$

$$
R^{2}=93,1 \quad D W=1,72 \quad F c=203,6
$$

onde

$T_{A L}-$ Fluxo de turistas alemäes

PIB $A L-$ Produto Interno Bruto da Alemanha;
${ }^{*}$ - Os números entre parenteses referem-se aos valores do Teste $t$ dos coeficientes.

ponto de se notar muitas semelhanças entre as configuraçōes das duas tendências - foram testadas algumas de suas variáveis determinantes, sobressaindo-se o câmbio real relativo entre a Argentina e o Brasil.

Ajustando-se a função apenas com as variáveis renda real mundial média e o número de turistas em $\mathrm{t}-1$, obtém-se resultados bastante razoáveis, mas, quando se inclui nesta função a variável $\mathrm{CR}(\mathrm{A} / \mathrm{B})$, melhora ainda mais a sua significância estatística: explica-se uma maior parcela do desvio do ano atípico de 1980. Os resultados desse ajustamento e as aproximaçōes entre os valores estimados com os reais podem ser observados na Figura 5.
FIGURA 5 - RECEPTIVO TOTAL DO BRASIL - CONFRONTO DOS RESULTADOS ESTIMADOS E OBSER VADOS - 1970 a 1986 (Base: $1970=100)$

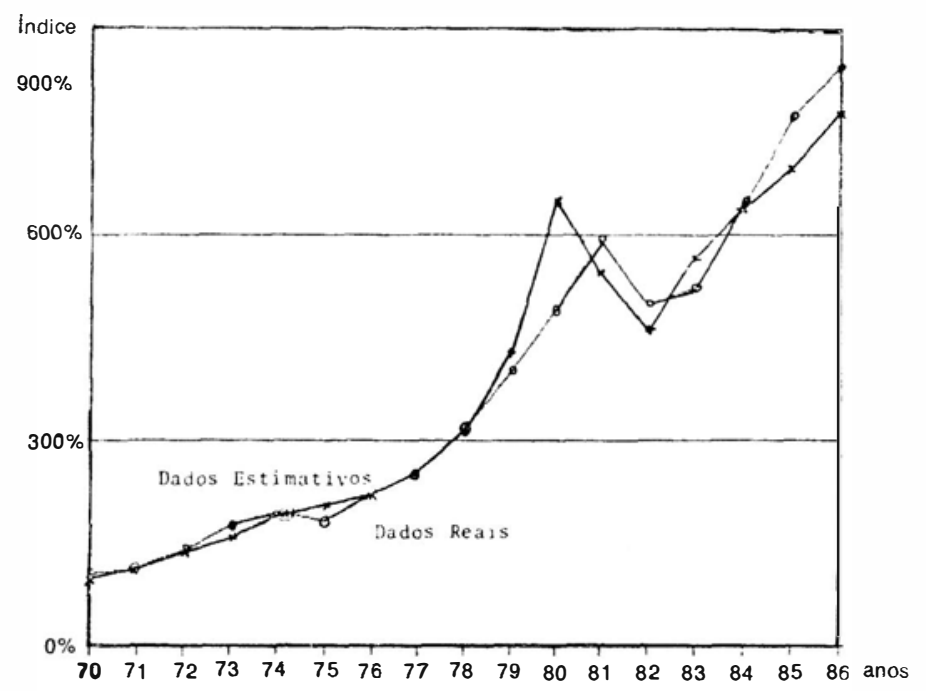

Fonte: Dados extraídos de Anuários Estatisticos da Embratur ${ }^{17}$.

Função estionada:

$L T=1,806+1,981(P I B)+0,423\left(L T_{t-1}\right)-0,112(C R A / B)$

$$
\begin{aligned}
& \begin{array}{l}
(-2.57)(3,02) \quad(2,36) \\
R^{2}=97,9 \% \quad D W=1,81
\end{array} \quad F c=203,8
\end{aligned}
$$

onde:

LT - Logaritmo do nímero de turistas internacionais no Brasil;

* Os valores entre paranteses referem-se aos valores do teste $t$ dos coeficientes.

No que se refere à previsão do receptivo total a partir de um sistema de modelos interativos, a solução depende basicamente da adequada formulação dos modelos parciais de demanda e da forma funcional da agregação. A principal restrição a essa forma alternativa de previsảo refere-se à necessidade de admitir-se, como constantes, as participaçōes relativas dos países componentes. Mas apresenta validade quando as previsões são feitas para o curto prazo.

O ajustamento da função agregativa, com a inclusão da variável tempo, é apresentado a seguir, e suas estimativas, confrontadas com os dados reais, podem ser observadas na Figura 6. 
FIGURA 6 - RECEPTIVO TOTAL DO BRASIL - FUNCĀO

AGREGATIVA: CONFRONTO DOS RESULTADOS ESTIMADOS E

OBSERVADOS - 1971 a 1986 (Base: $1970=100)$

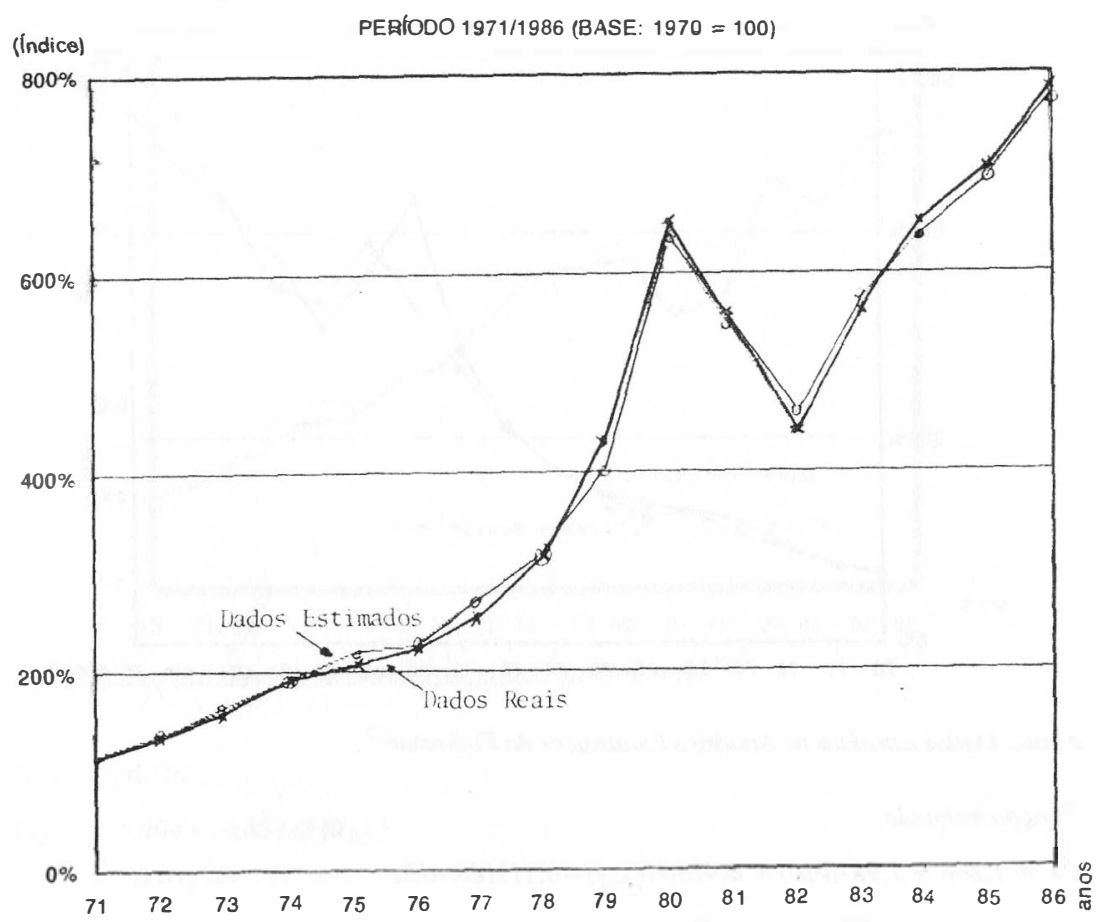

Fonte: Dados extraidos de Anuários Estatísticos da Embratur.

Função estimnativa:

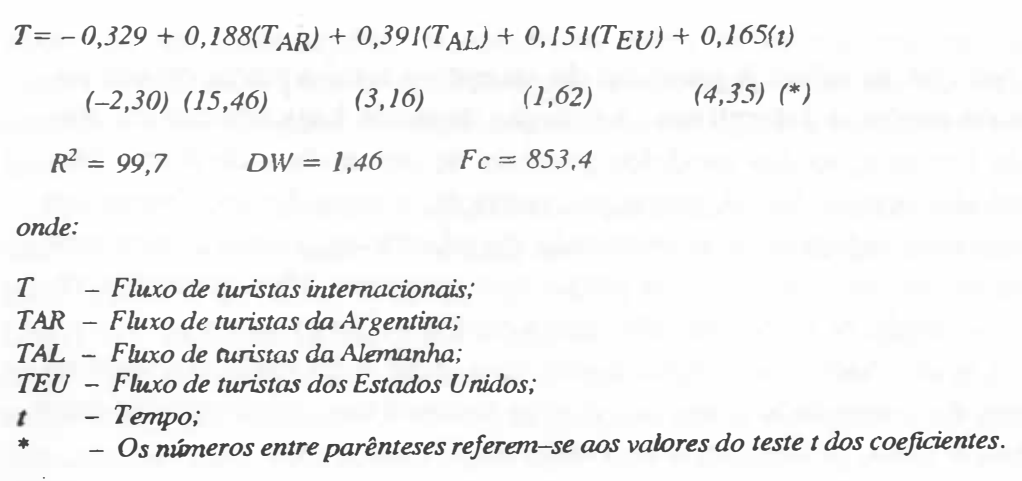

\section{CONCLUSÃo}

Os modelos econométricos, formulados em caráter experimental para o caso brasileiro, revelaram resultados auspiciosos e consistentes com as proposiçōes teóricas. Os fluxos intra-regionais, representados pelo turismo emissivo da Argentina, revelaram-se mais sensfveis às flutuaçōes conjunturais dos fatores relativos da oferta - câmbio e preços relativos -, enquanto que os fluxos inter-regionais, representados pelos Estados Unidos e a Alemanha, sāo determinados, especialmente, pelos fatores de demanda e da conjuntura internacional.

Ressalta-se que a destinaçāo Brasil é apenas marginal para esses importantes centros emissores mundiais - entre 0,1 e $0,5 \%$ de seus totais -, de modo que um acontecimento especial ou uma campanha promocional, por exemplo, podem refletir-se em mudanças de escala, com implicaçōes na forma da função ou no intercepto, se o ritmo subseqüente for mantido constante, como o verificado para o caso dos Estados Unidos, a partir de 1983, embora com resultados pouco significativos.

Os estudos que tratam da construção de modelos teorométricos requerem, para o seu desenvolvimento e aprimoramento, esforços acadêmicos concentrados e multidisciplinares. Tornam-se mais realistas e viáveis, quando apoiados por uma estrutura de informática e baseados em estatísticas de boa qualidade. Os resultados experimentais deste trabalho e os dados de outros estudos apresentados pernitem reconhecer a validade desse tratamento científico em apoio ao planejamento turístico, contribuindo para reduzir a margem de erro das previsões e melhorar a fundamentação das decisóes de política econômica

\section{Referências Bibliograficas}

1. OMT. Secretaria Geral. Efectos del twivino en la economia. Madrid: OMT, 1978. p. $14-5$.

2. USP. Fundaçāo Instituto de Pesquisas Económicas. Multiplicadores de renda e emprego para o Brasil. São Paulo: FEA/USP, dez. 1984116 p.

3. OMT. Secretaria Geral. Estudio económico del turismo mundial. Madrid: OMT, 1984 $102 \mathrm{p}$.

4. OMT. Secretaria Geral. Estudio econónico del turiono mundial. Madrid: OMT, 1986 $95 \mathrm{p}$.

5. SESSA. Alberto. Turismo e poltitica de desenvolvimento. Porto Alegre: Uniontur, 1982

6. RABAHY. Wilson Abrahāo. Fundamentos econométricos e ertudos económicos no pla nejornento turístico. São Paulo: ECA/USP, 1988. 313 p. (Tese de Livro-docencia) 
7. KIRSTEN, José Tiacci. Teoria dos modelos. Sāo Paulo: FEA/USP, 1983. 39 p. (Apostila do Departamento de Economia).

8. RABAHY, Wilson Abrahão. Subsídios para uma política de desenvolvimento das atividades turisticas: modelos potencial e de desempenho real. Sāo Paulo: ECA/USP, 1980. 189 p. (Tese de Mestrado)

9. HAA VELMO apud BARBANCHO, Alfonso G. Fundamentos e possibitidodes da econometria. Rio de Janeiro: Ariel Editora, 1970. p. 20.

10. TINTNER, Gerhard. Econometrics. 2ª ed. Nova York: John Wiley \& Sons, 1967. 117. p.

11. INCHAUSTI, Angel Alcaide. La teorometria, como nueva ciencia, al servicio de la investigación turística. Estudios turisticos. Madrid, n. especial, p. 123-31, 1967. (Rev. do Instituto de Estudios Turísticos).

12. INCHAUSTI, Angel Alcaide. Econometria del turismo. Estudios 4, p. 5-30, 1964. (Rev. do Instituto de Estudios Turísticos)

13. SAN ROMÁN, Antonio Pulido. Aplicación de la econometria al análisis del fenómeno turístico. Estudios turísticos. Madrid, n. 12, p. 5-43, out. dez. 1966. (Rev. do Instituto de Estudios Turísticos)

14. VALAVANIS, Stefan. Econometrics. Nova York: McGraw-Hill, 1958. p. 1-2.

15. PALOMO, Miguel Figuerola. Economia turística: elementos de uma teoria económica del turismo y métodos para su análisis cuantitativo. Madrid: Inınasa, 1979. p. 243 (Tese de Doutoramento)

16. OMT. Secretaria Geral. Guidelines for constructing a tourist price index: basic methodology. Sofia: OMT, 1985. 43 p.

17. EMPRESA BRASILEIRA DE TURISMO - EMBRATUR. Anuário Estatístico 1970 a 1987. Rio de Janeiro: Embratur, 1970 a 1987.

18. ARTUS, Jacques R. An econometric analysis of international travel. International Monetary Fund Staff Papers, p. 579.613, dez. 1971. 